\title{
Non-medical factors on choice of delivery (CS/NVD) in hospitals of Tehran University of Medical Sciences
}

\author{
Rahim Ostovar ${ }^{1 *}$, Batool Hossein Rashidi ${ }^{2}$, Fedeyh Haghallahi' ${ }^{2}$,Mohammad Fararoei ${ }^{3}$, \\ Mahin Rasouli ${ }^{4}$, Ebrahim Naeimi ${ }^{5}$ \\ ${ }^{1}$ Social Determinants of Health Research Center, School of Health, Yasuj University of Medical Sciences, Yasuj, Iran \\ ${ }^{2}$ Vali-e-Asr Reproductive Health Research Center, Tehran University of Medical Sciences, Tehran, Iran \\ ${ }^{3}$ Department of Public Health, School of Health, Yasuj University of Medical Sciences, Yasuj, Iran \\ ${ }^{4}$ Department of Statistics and Epidemiology, School of Health, Tehran University of Medical Sciences, Tehran, Iran \\ ${ }^{5}$ Public Health Department, School of Health, Yasuj University of Medical Sciences, Yasuj, Iran \\ Email: ${ }^{*}$ rahimostovar@yahoo.com
}

Received 29 September 2012; revised 30 October 2012; accepted 9 November 2012

\begin{abstract}
Background: Kind of delivery affect many aspects of individuals, families and health systems situations. The aim of this study was to identify the Role of nonmedical factors on choice of delivery (CS/NVD) in hospitals affiliated to Tehran University of Medical Sciences. Materials and Method: This cross-sectional study was performed to identify the factors involved in the choice of delivery (CS/NVD) among women attending hospitals affiliated to Tehran University of Medical Sciences. Data was derived from the medical records of women who gave birth in the hospitals. Results: A significant statistical relationship was found between factors such as age of mother, level of education, occupational status, type of previous delivery, person supervising the pregnancy and dissatisfaction about delivery were more frequent in women who underwent CS than those who gave birth by NVD. Conclusion: The highly increasing rise in the rate of unnecessary CS during throughout the world, and its adverse effect on maternal and child health, the financial burden imposed on families and health systems, has highlighted the importance of studies to identify the non-medical factors that affect decisionmaking concerning type of delivery as well as to determine the appropriate medical indications of CS.
\end{abstract}

Keywords: Cesarean Section; Normal Vaginal Delivery; Inappropriate Health Care; Health System

\section{INTRODUCTION}

Cesarean section is one of the main concerns of the health authorities and health systems of developed and

${ }^{*}$ Corresponding author. developing countries. With a rate that has increased several fold in most countries, values of around $23.5 \%, 40 \%$, $36 \%, 23.3 \%$ and $22.4 \%$ have been reported for the US, Chile, Brazil, Taiwan and Italy, respectively [1-4]. These rates are much higher than those suggested by the WHO, according to which a rate of around $15 \%$ has scientific and medical indications, and values higher than this are considered as unnecessary or inappropriate [5]. Many authors highlight that unnecessary CS can increase mortality and complications in women and children. Furthermore, more resources are misused in CS than NVD [6-8]. Many studies show that CS rate is affected by factors such as indications in the mother including her socioeconomic status, suggestions made in health centers, and the decision of the doctor or health personnel [9-11]. Other researchers believe that the non-medical factors affecting increased CS rates include maternal factors, such as mother's demand, age, previous experience of delivery, level of education, occupation, economic status and other factors including, type of insurance coverage, type of hospital and its facilities, presence of bedside nurses, type of previous delivery, fear of severe labor pain, doctor's decision, patient's rights, freedom of mother to choose type of delivery, legal issues, financial coverage and payment of costs of delivery, estimated cost of CS or NVD, and induction of type of delivery by doctors [12-16]. The large differences in CS rates reported from different institutions, regions, and gynecologists cannot be attributed to medical or obstetric factors [17].

One of the problems faced by the health systems during the past few years is the increasing health service and health care costs; one main cause of this increase is unnecessary or inappropriate services [18]. The results of various studies show that around $10 \%-40 \%$ of the health care provided in health institutes are actually unnecessary $[19,20]$. A recently designed economic model, 
which showed the costs of non-medically indicated CS in the National Health System of UK, estimated that annually around 10.9 - 14.8 million additional pounds must be spent by the health system and the mean saved expenses for each NVD and appropriate CS was around 1257 pounds [21]. According to the last study performed by the Ministry of Health and Medical Education of Iran in 2006, CS rate was estimated to be around $47 \%$ in Iran and $52 \%$ in Tehran [22]. Regarding the policies of the Ministry of Health to reduce CS rate and the need to assess the main non-medical factors involved in CS, we performed this study to identify the non-medical factors affecting choice of delivery.

\section{MATERIALS AND METHOD}

This descriptive cross-sectional study was performed between 2008-2009 in hospitals affiliated to Tehran University of Medical Sciences (TUMS). Regarding the prevalence of CS in Iran and Tehran, a specimen volume of 250 women who had undergone CS and 250 women who had undergone NVD were selected. Data was obtained from the medical records of mothers who had delivered in the hospitals under study and complementary data such as age of marriage, decision maker for type of the delivery, type of previous delivery, education and so on, was obtained by interview and by completing a questionnaire designed for this purpose. Trained midwives were chosen to attend the hospitals, review the medical records, interview the mothers, and complete the questionnaires. In some cases, complementary data was obtained after the mother's condition became stable or by contacting her via telephone. After compiling the data, SPSS software and statistical tests (Chi-Square test and logistic regression method) were used for statistical analysis and compare factors in the two groups under study. This study approved by the Deputy of Research of Theran University of Medical Sciences.

\section{RESULTS}

Data collected from the medical records of women who delivered in hospitals affiliated to TUMS, were analyzed as follows (Table 1).

According to Table 1, most of the deliveries took place in 18 - 35 years of age which was significantly different between the two groups $(\mathrm{P}<0.001)$. NVD is more common in women aged more than 35 years, compared to other age groups $(\mathrm{P}<0.05)$. Results show that most of the women undergone NVD or CS were primigravida (52\%). CS increased as number of pregnancies increased, such that four or more pregnancies comprise $7.2 \%$ of all CS deliveries; this was $4.4 \%$ for NVD. A significant statistical relationship was found between current and previous choice of delivery $(\mathrm{p}<0.05)$. Results show that most mothers who had previous history of NVD had primary to secondary or high school education, respectively (43.2\% and $41.6 \%$ ). Highest values are also seen in case of women who had undergone CS $(20 \%$ and $57.6 \%$ ) but illiteracy rate was much higher among women who delivered by NVD than those who delivered by CS (5.6\% vs. $1.2 \%)$. Interestingly, CS rate increased with advancing literacy, such that $19.6 \%$ of women who had undergone CS, had university education, while this was $9.6 \%$ in case of women with NVD. The statistical relationship between level of education and choice of delivery was significant $(p<0.05)$. Considering the findings of Table 1, overall occupation rate was $11.6 \%$; $17.6 \%$ in case of women with CS and 5.6\% in case of women with NVD. Housewives comprised $94.4 \%$ and $82.4 \%$ of women who had undergone NVD and CS, respectively. A significant statistical relationship was found to exist between occupational status and choice of delivery $(p<0.05)$. The findings of our study show that amongst women who received prenatal care, most were seen by gynecologists. $67.2 \%$ and $34 \%$ of women who were seen by gynecologists delivered by CS and NVD, respectively. Table 1 shows decision about choice of delivery. $67.2 \%$ of mothers who delivered by NVD, opted for NVD themselves and only $15.2 \%$ of them did so due to physician orders. However, only $16.4 \%$ of mothers decided to deliver by CS themselves and 53.6\% did so due to their doctor's decision. The statistical relationship between level of decision maker and choice of delivery was significant $(p<0.05)$. Findings show the insurance coverage status in regards to choice of delivery. Overall insurance coverage was $74.6 \%$, which was $70 \%$ for NVD and $79.2 \%$ for CS. These variables had no significant statistical difference with each other. The state of complementary insurance is shown in Table 1. According to the table, $24.6 \%$ of the cases under study had complementary insurance, of which $20.2 \%$ comprised NVD cases. According to the results, $1.6 \%$ and $18 \%$ of women with NVD and CS had experienced abortion, respectively, which meant that women who had history of abortion had preference to deliver by CS. Women with history of delivery of dead babies showed almost the same pattern, although this relationship was not significant. As seen in Table 2, out of the 128 women who had history of previous NVD, 127 (99\%) delivered by NVD again. However, in the CS group, out of the 106 women with previous delivery, 71 delivered by CS. Thus most women, who had previously delivered by NVD, chose to deliver by NVD again and most women with previous CS chose to deliver by CS again.

We used logistic regression method for statistical analysis in this study too. Covariates model selection was 
Table 1. Comparison of some variables between types of delivery in study population.

\begin{tabular}{|c|c|c|c|c|c|c|c|}
\hline \multirow{3}{*}{$\begin{array}{l}\text { Variables } \\
\text { Age: }<18\end{array}$} & \multicolumn{4}{|c|}{ type of delivery } & \multirow{2}{*}{\multicolumn{2}{|c|}{ Total \% }} & \multirow{3}{*}{ P. Value } \\
\hline & \multicolumn{2}{|c|}{ Vaginal (frequency \%) } & \multicolumn{2}{|c|}{ Cesarean (frequency \%) } & & & \\
\hline & 7 & 100.0 & 0 & 100.0 & 7 & 100.0 & \\
\hline $18-35$ & 228 & 50.5 & 215 & 48.5 & 443 & 100.0 & ${ }^{*} \mathrm{P}<0.001$ \\
\hline$>35$ & 15 & 30.0 & 35 & 70.0 & 50 & 100.0 & \\
\hline Age of marriage: $<19$ & 97 & 61.4 & 61 & 38.6 & 158 & 100.0 & \\
\hline $19-30$ & 149 & 45.7 & 177 & 54.3 & 326 & 100.0 & $\mathrm{P}=0.001$ \\
\hline$>30$ & 4 & 25.0 & 12 & 75.0 & 16 & 100.0 & \\
\hline $\begin{array}{l}\text { Type of previous delivery: } \\
\text { Without delivery }\end{array}$ & 122 & 46 & 144 & 54 & 266 & 100.0 & \\
\hline Vaginal & 127 & 78.4 & 35 & 21.6 & 162 & 100.0 & P 0.001 \\
\hline Cesarean & 1 & 1.4 & 71 & 98.6 & 72 & 100.0 & \\
\hline Number of pregnancies 1 pregnancy & 115 & 48.3 & 123 & 51.7 & 238 & 100.0 & \\
\hline 2 pregnancies & 124 & 53.2 & 109 & 46.8 & 233 & 100.0 & $\mathrm{P}<0.001$ \\
\hline 3 and more pregnancies & 11 & 37.9 & 18 & 62.1 & 29 & 100.0 & \\
\hline Still birth (nullipara) & 116 & 48.5 & 123 & 51.5 & 239 & 100.0 & \\
\hline Yes & 2 & 16.7 & 10 & 83.3 & 12 & 100.0 & $\mathrm{P}=0.040$ \\
\hline No & 132 & 53.0 & 117 & 47.0 & 249 & 100.0 & \\
\hline Education: Illiterate & 14 & 82.4 & 3 & 17.6 & 17 & 100.0 & \\
\hline Primary \& secondary & 108 & 68.4 & 50 & 36.1 & 158 & 100.0 & \\
\hline High school & 104 & 41.9 & 144 & 58.1 & 248 & 100.0 & 0 \\
\hline University & 24 & 31.2 & 53 & 68.8 & 77 & 100.0 & \\
\hline Occupation: Occupied & 13 & 5.0 & 248 & 95.0 & 261 & 100.0 & \\
\hline Without job & 237 & 99.2 & 2 & 0.8 & 239 & 100.0 & \\
\hline Consult: & 15 & 93.8 & 1 & 6.2 & 16 & 100.0 & \\
\hline Yes & 141 & 39.8 & 213 & 60.2 & 354 & 100.0 & $\mathrm{P}<0.001$ \\
\hline No & 94 & 72.3 & 36 & 27.7 & 130 & 100.0 & \\
\hline $\begin{array}{l}\text { Decision maker for type of the delivery: } \\
\text { Without previous decision }\end{array}$ & 43 & 36.4 & 75 & 63.6 & 118 & 100.0 & \\
\hline herself & 98 & 76.6 & 30 & 23.4 & 128 & 100.0 & $\mathrm{P}<0.001$ \\
\hline husband & 11 & 84.6 & 2 & 15.4 & 13 & 100.0 & \\
\hline Physician & 98 & 40.7 & 143 & 59.3 & 241 & 100.0 & \\
\hline Medical insurance: Covered & 176 & 47.2 & 197 & 52.8 & 373 & 100.0 & \\
\hline Not covered & 74 & 58.3 & 53 & 41.7 & 127 & 100.0 & 0.02 \\
\hline Complementary insurance & 89 & 63.6 & 51 & 36.4 & 140 & 100.0 & \\
\hline Yes & 23 & 18.5 & 101 & 81.5 & 124 & 100.0 & $\mathrm{P}<0.001$ \\
\hline No & 138 & 58.5 & 98 & 41.5 & 236 & 100.0 & \\
\hline
\end{tabular}

*age group $<18$ years is combined with age group 18 - 35 years for Chi-Squire test. 
conducted by backward selection. Finally regression analysis showed that women age, level of education, consultation with mothers before delivery, mother request for type of delivery, have scientific relationship with the type of delivery $(\mathrm{P}<0.01)$ (Table 2).

\section{DISCUSSION}

This study was performed in order to determine the nonmedical factors affecting choice of delivery in women who gave birth in hospitals affiliated to TUMS in the year 2008-2009. The population under study comprised of 250 cases of NVD and 250 cases of CS, who were studied simultaneously. Previous studies show that unnecessary and inappropriate services are provided in health and treatment centers $[19,20,23]$ and that these services impose a large financial burden not only on the health system but also on the society. Since CS is one of the most common surgical operations which is alarmingly increasing throughout the world, including Iran $[1-5,22]$, the performance of a study on the state of delivery and factors affecting it was one of the priorities of the health system, especially in the family health sector.

Table 2. Relationship between some variables and type of delivery (Regression test).

\begin{tabular}{|c|c|c|c|c|}
\hline variables & B & S.E. & Sig. & $\operatorname{Exp}(\mathrm{B})$ \\
\hline Still birth (nullipara) & Ref & - & - & - \\
\hline Yes & 10.334 & 2.686 & 0.000 & 30767.949 \\
\hline No & 4.040 & 1.632 & 0.013 & 56.837 \\
\hline $\begin{array}{l}\text { Type of previous delivery } \\
\text { (without previous delivery) }\end{array}$ & Ref & - & - & - \\
\hline Vaginal & -9.344 & 7.162 & 0.192 & 0.000 \\
\hline Cesarean & -8.631 & 7.114 & 0.225 & 0.000 \\
\hline Sex of child (male) & Ref & - & - & - \\
\hline Female & 2.550 & 1.266 & 0.044 & 12.801 \\
\hline Education (Illiterate) & Ref & - & - & - \\
\hline Primary\& secondry & 1.793 & 1.968 & 0.362 & 6.010 \\
\hline High school & 5.093 & 1.734 & 0.003 & 162.882 \\
\hline University levels & 4.883 & 1.520 & 0.001 & 132.040 \\
\hline Occupation (occupied) & Ref & - & - & - \\
\hline Without job & -11.693 & 2.556 & 0.000 & 0.000 \\
\hline $\begin{array}{l}\text { Decision maker (without } \\
\text { previous decision) }\end{array}$ & Ref & - & - & - \\
\hline Herself & 1.676 & 7.904 & 0.832 & 5.343 \\
\hline Husband & -1.691 & 7.982 & 0.832 & 0.184 \\
\hline Physician & 2.557 & 7.949 & 0.748 & 12.897 \\
\hline
\end{tabular}

One of the important factors is the choice of hospital. In our previous studies, CS rate was much higher in private than public hospitals and inappropriate CS comprises around $47 \%$ of all CS $[24,25]$. The difference in CS rate in public and private hospitals is mainly related to factors such as management and supervision, large differences between the costs of public and private hospitals, much higher costs of CS as compared to NVD, especially in the private sector and the therapeutic insurance coverage. Another factor is age of mother at time of delivery [25]. In developed countries, level of education of women, occupation or high occupational rank, and advancing age of marriage are factors considered to increase CS rate. Although psychiatric, mental and even anatomical factors have been shown to increase the rate of CS in higher ages [3], but most studies have shown the role, decision and emphasis of the treating physicians to be more effective in choosing the choice of delivery in mothers with higher ages, than maternal physical, mental or psychiatric status [25-27]. In our study, CS rate was considerably higher than NVD rate in women aged above 30 years $(12.6 \%, 6.2 \%$ and $2 \%$ of all deliveries) (Table 1). The higher age of mothers could be attributed to other variables such as their advancing age of marriage, higher number of pregnancies, level of education and occupation. In our study, age of marriage, level of education and occupational status of women who delivered by CS were relatively higher than women who delivered by NVD. Also, chi-square test showed a significant statistical relationship between choice of delivery and occupation, level of education and age of mother during pregnancy $(\mathrm{P}<0.05)$. Women undergoing CS can usually be considered to have above high-school level of education, be employed, be aware of the two processes of deliveries, have higher age of pregnancy and feelings of freedom and independence. Although freedom and independence supporters believe that the right to choose the method of delivery should be given to fully aware mothers [28-30]. According to the FIGO Clinical Guideline, performance of CS without a medical reason, is not consistent with medical ethics [31]. On the other hand, according to many specialists, pregnancy is not a disease and NVD is the natural result of a pregnancy, for which the mother and father, and not the medical specialists, must accept responsibility [32]. In addition, the freedom of women to choose the choice of delivery is usually not a logical decision regarding the outcome of pregnancy and maternal health. Factors which affect the mother's decision to undergo CS include fear of NVD, the mother's personality and mistrust which must be investigated. Good, satisfactory and independent counseling regarding NVD could prove beneficial and the fact that around half of the women who had previous CS opted for NVD after these counseling sessions was a very good experience in the 
field of obstetrics as well as for the health system [33]. Another topic which is dealt with in our study as well as in many studies and discussions related to obstetrics, is the type of previous delivery and its effect on deciding for future deliveries. In the present study, out of the 250 women who delivered by NVD, 128 women $(42.2 \%)$ had their second delivery, 127 ( $>99 \%$ ) of whom had delivered by NVD before. However, in case of the 250 women who had delivered by CS, 106 cases had a second delivery, $50 \%$ of whom had previously delivered by $\mathrm{CS}$, which means that the rate of CS due to previous CS is more than $50 \%$. Chi-square test shows a significant statistical relationship between choice of previous and current delivery. One of the important actions taken to reduce the rate of CS in the US and Europe, especially in the UK, is a program to help women who had undergone $\mathrm{CS}$ in their previous pregnancy, to give birth by NVD. In this way the rate of vaginal birth after cesarean (VBAC) rose from $18.9 \%$ in 1989 to $27.4 \%$ in 1997 . This rate was more rapid in European countries and it comprises almost $50 \%$ of all NVDs [34,35]. Published scientific data emphasize that around $60 \%-80 \%$ of NVDs will be successful after CS. Interestingly; success rates were higher in women who had a previous NVD or CS due to indications such as breech presentation. In any case, these women must be chosen very carefully and they should receive specialized care during delivery which should be performed in well-equipped hospitals and in the presence of expert specialists [36-38]. Prenatal care is another factor studied. Most $(>98 \%)$ of the women under study received prenatal care. Most (67.2\%) of the women who underwent CS were under the supervision of gynecologists while most of the women who delivered by NVD seen by midwives or health centers and only $34 \%$ were supervised by gynecologists. This high rate of CS can be attributed to the prenatal care which was given by gynecologists, especially since $53.6 \%$ of women who underwent CS stated that they opted for CS due to their doctor's decision. These figures were only $13.6 \%$ in case women undergoing NVD. Many studies have shown that the supervising health personnel, their character or personality, and their level of education and occupation to be effective in the decision made about the choice of delivery [39-42]. Another important topic which is discussed mainly by gynecologists or supervising persons is the mother's demand and her approval to perform CS. As previously stated, this may be attributed to the mother's independence, freedom of choice, and patient's rights. As seen in the current study, only $16 \%$ of women opted for CS themselves, while around 54\% stated that they chose to undergo CS due to their physician's decision. It is noteworthy that most dissatisfaction towards CS was due to pain and immobility and that the main reason for choosing CS was their fear of pain of NVD. Considering all the above-mentioned factors, we could conclude that first, information asymmetry and the probability of the induced demand to them by treating physicians may result in the mother to rely on her physician and to accept his or her orders. Second, lack of knowledge and experience concerning choice of delivery (fear of pain and dissatisfaction towards CS) may affect their decision regarding type of delivery. These factors must be considered by policy makers and health system executives in the agenda they set in the health sector especially regarding maternal health care. Another important factor is the state of insurance coverage and the financial help mothers receive. According to our findings, insurance coverage was $74.6 \%$ in the population under study. In other words, one quarter of the population, which mainly includes women who delivered by NVD (30\%), had no form of financial coverage (Table 1). More important is complementary insurance coverage, which covered $40.4 \%$ and $8.8 \%$ of women with CS and NVD, respectively. Different studies have pointed out the role insurance companies play in promoting unnecessary health services, including CS. In a study in the US it was seen that CS rates were higher among women who were under private insurance coverage (high financial support) than those receiving Health Maintenance Organization (HMO) support [42-44]. Another problem of the health sector is Moral Hazards, in which because the costs are mainly paid by the insurance companies, unnecessary and sometimes inappropriate procedures are sought not only by the patients, but also recommended by insurance personnel. Another important topic is that in the National Health System of Iran, CS and normal vaginal delivery costs which are paid by insurance companies are done globally, but this rate is very variable. Also, the payable cost of CS is many-fold that of NVD, which is more evident in the private than the public sector. This can intensify induced demand for CS and affect ethical dangers. Finally, fear of legal or penal problems and the lack of clear and adequate laws and regulations to support specialists as well as the lack of necessary standards and sufficient insurance coverage and support regarding medical procedures has resulted in the topic of Defensive Medicine in which physicians and obstetricians believe that they can overcome the patient's concerns while observing rules and regulations much easier by performing CS [45-48].

\section{CONCLUSION}

On the whole, we must state that the rapidly rising rates of $\mathrm{CS}$ and its associated consequences is one of the main concerns of policy makers and Health System managers in all societies today. In addition to the medical factors and indications of this procedure, the necessity of which must be investigated, many non-medical factors are also 
involved in its rise. This study investigated a few of the most important non-medical factors affecting choice of delivery. Programming such that CS rate becomes more logical depends on a serious review of different aspects including social, economic, and cultural problems, payable systems, including financial support systems, the medical and paramedical education system, as well as the availability of hospital equipment and facilities. If related research is not performed and scientific solutions are not sought, none of the measures could be a suitable and practical solution to reducing unnecessary and inappropriate procedures or surgery, including CS.

\section{ACKNOWLEDGEMENTS}

We would like to greatly thank the Deputy of Research of TUMS for their financial support as well as the Vali-e-Asr Infertility Research Center.

\section{REFERENCES}

[1] Kabir, A.A., Steinmann, W.C., Myers, L., Khan, M.M., Herrera, E.A., Yu, S. and Jooma, N. (2004) Unnecessary cesarean delivery in Louisiana: An analysis of birth certificate data. American Journal of Obstetrics and Gynecology, 190, 10-19.

[2] Lin, H.-C. and Xirasagar. S. (2005) Maternal age and the likelihood of a maternal request for cesarean delivery: A 5-year population-based study. American Journal of $\mathrm{Ob}$ stetrics and Gynecology, 192, 848-855. doi:10.1016/j.ajog.2004.09.133

[3] Gomes, U.A., Silva, A.A., Bettiol, H. and Barbieri, M.A. (1999) Risk factors for the increasing caesarean section rate in Southeast Brazil: A comparison of two birth cohorts, 1978-1979 and 1994. International Journal of Epidemiology, 28, 687-694. doi:10.1093/ije/28.4.687

[4] Evans, L. (1995) Italy has Europe's highest caesarean section rate. British Medical Journal, 310, 487. doi:10.1136/bmj.310.6978.487

[5] World Health Organization (1985) Appropriate technology for birth. Lancet, 2, 436-437.

[6] Shearer, E.L. (1993) Cesarean section: Medical benefits and costs. Social Science \& Medicine, 37, 1223-1231. doi:10.1016/0277-9536(93)90334-Z

[7] Goer, H. (2001) The case against elective cesarean section. The Journal of Perinatal \& Neonatal Nursing, 15, 23-38.

[8] Herng, C.L., Tzong, C.S., Chao, H.T. and Senyeong, K. (2004) Association between maternal age and the likelyhood of a cesarean section: A population-based multivariate logistic regression analysis. Acta Obstetricia et Gynecologica Scandinavica, 83, 1178-1183.

[9] Lavender, T., Hofmeyr, G.J., Neilson, J.P., Kingdon, C. and Gyte, G.M.L. (2006) Caesarean section for nonmedical reasons at term. The Cochrane Library, The Cochrane Collaboration Volume (4).

[10] Gould, J.B., Davey, B. and Stafford, R.S. (1989) Socio- economic differences in rates of cesarean section. The New England Journal of Medicine, 321, 233-239. doi:10.1056/NEJM198907273210406

[11] Newton, E.R. and Higgins, C.S. (1989) Factors associated with hospitalspecific cesarean birth rates. Journal of Reproductive Medicine, 34, 407-411.

[12] Burns, L.R., Geller, S.E. and Wholey, D.R. (1995) The effect of physician factors on the cesarean section decision. Medical Care, 33, 365-382. doi:10.1097/00005650-199504000-00004

[13] Goer, H. (2001) The case against elective cesarean section. Journal of Perinatal and Neonatal Nursing, 15, 2338.

[14] Lowdon, G. and Derrick, D. (2002) Caesarean section or vaginal birth-What difference does it make? AIMS Quarterly Journal, 14, 1-4.

[15] McAleese, S. (2000) Caesarean section for maternal choice? Midwifery Matters, 84, 12-14.

[16] Gamble, J. and Creedy, D.K. (2000) Women's request for cesarean section: A critique of the literature. Birth, 27, 256-263. doi:10.1046/j.1523-536x.2000.00256.x

[17] Freeman, R.K., Cohen, A.W., Depp III, R., Frigoletto Jr., F.D., Hankins, G.D.V., Lieberman, E., et al. (2000) Evaluation of cesarean delivery. The American College of Obstetricians and Gynecologists, Washington DC.

[18] Nicollier, F.A., Vader, J.P., Froehlich, F., Gonvers, J.J. and Burnand, B. (2003) Development of appropriateness criteria for colonoscopy. International Journal of Health Care, 15, 15-22.

[19] Paul, G.S., James, P.K., Steven, J., Lucian, L.L., Caren, J.K. and Park, R.E. (1998) The reproducibility of a method to identify the overuse and under use of medical procedures. The New England Journal of Medicine, 338, 1888-1895. doi:10.1056/NEJM199806253382607

[20] Phelps, E.C. (1993) The methodologic foundations of studies of the appropriateness of medical care. The New England Journal of Medicine, 1329, 1241-1245. doi:10.1056/NEJM199310213291707

[21] The National Collaborating Centre for Women's and Childrens Health (2004) Caesarean section clinical guideline. RCOG Press, London.

[22] The Iranian Ministry of Health (2005) The fertility health assessment program, family health section.

[23] Liu, X. and Miles, A. (1999) Evaluating payment mechanisms: How can we measure unnecessary care? Health Policy and Planning, 14, 409-413.

doi:10.1093/heapol/14.4.409

[24] Ostvar, R., Rashidian, A., Pourreza, A., Rashidi, B.H., Hantoushzadeh, S. and Eftekhar, A.H. (2010) Developing criteria for Cesarean section using the RAND appropriateness method 2010. BMC Pregnancy and Childbirth, 52, $1-8$.

[25] Peipert, J.F. and Bracken, M.B. (1993) Maternal age: An independent risk factor for cesarean delivery. Obstetrics \& Gynecology, 81, 200-205.

[26] Martel, M., Wacholder, S., Lippman, A., Brohan, J. and Hamilton, E. (1987) Maternal age and primary cesarean 
section rates: A multivariate analysis. American Journal of Obstetrics \& Gynecology, 156, 305-308.

[27] Ezra, Y., McParland, P. and Farine, D. (1995) High delivery intervention rates in nulliparous women over age 35. European Journal of Obstetrics \& Gynecology and Reproductive Biology, 62, 203-207. doi:10.1016/0301-2115(95)02201-H

[28] Paterson-Brown, S., Amu, O., Rajendran, S. and Bolaji, I.I. (1998) Should doctors perform an elective caesarean section on request? British Medical Journal, 317, 462467.

[29] Sultan, A.H. and Stanton, S.L. (1996) Preserving the pelvic floor and perineum during childbirth-elective caesarean section? British Journal of Obstetrics and Gynaecology, 103, 731-734. doi:10.1111/j.1471-0528.1996.tb09864.x

[30] Feldman, G.B. and Freiman, J.A. (1985) Prophylactic cesarean sectio at term? The New England Journal of Medicine, 312, 1265-1267. doi:10.1056/NEJM198505093121926

[31] FIGO Committee for the Ethical Aspects of Human Reproduction and Women's Health (1999) Ethical aspects regarding cesarean delivery for non-medical reasons. International Journal of Gynecology \& Obstetrics, 64, 317-322. doi:10.1016/S0020-7292(98)00266-5

[32] Wagner, M. (2000) Choosing caesarean section. Lancet, 356, 1677-1680. doi:10.1016/S0140-6736(00)03169-X

[33] Ryding, E.L. (1993) Investigation of 33 women who demanded a cesarean section for personal reasons. Acta Obstetricia et Gynecologica Scandinavica, 72, 280-285. doi:10.3109/00016349309068038

[34] Ventura, S.J., Martin, J.A., Curtin, S.C. and Mathews, T.J. (1999) Birth: Final data for 1997. National Vital Statistics Reports, 47, 1-83.

[35] Notzon, F.C., Cnattingius, S., Bergsjo, P., Cole, S., Taffel, S., Irgens, L., et al. (1994) Cesarean section delivery in the 1980s: International comparison by indication. American Journal of Obstetrics \& Gynecology, 170, 495-504.

[36] Rosen, M.G., Dickinson, J.C. and Westhoff, C.L. (1991) Vaginal birth after cesarean: A meta-analysis of morbidity and mortality. Obstetrics \& Gynecology, 77, 465-470.

[37] Flamm, B.L. (1995) Vaginal birth after cesarean section. In: Flamm, B.L. and Quilligan, E.J., Eds., Cesarean section: Guidelines for appropriate utilization. Springer-
Verlag, New York, 51-64.

[38] Pridjian, G. (1992) Labor after prior cesarean section. Clinical Obstetrics and Gynecology, 35, 445-456. doi:10.1097/00003081-199209000-00004

[39] Carpenter, M.W., Soule, D., Yates, W.T. and Meeker, C.I. (1987) Practice environment is associated with obstetric decision making regarding abnormal labor. Obstetrics \& Gynecology, 70, 657-662.

[40] DeMott, R.K. and Sandmire, H.F. (1992) The Green Bay cesarean section study. II. The physician factor as a determinant of cesarean birth rates for failed labor. American Journal of Obstetrics \& Gynecology, 166, 1799-1806, Discussion 1806-1810.

[41] Hodnett, E. (1996) Nursing support of the laboring woman. Journal of Obstetric, Gynecologic, and Neonatal Nursing, 25, 257-264. doi:10.1111/j.1552-6909.1996.tb02434.x

[42] Hueston, W.J. (1995) Site-to-site variation in the factors affecting cesarean section rates. Archives of Family Medicine, 4, 346-351.

[43] Lieberman, E. (1997) Predictors of cesarean delivery. Current Problems in Obstetrics, Gynecology, and Fertility, 20, 98-131.

[44] McCloskey, L., Petitti, D.B. and Hobel, C.J. (1992) Variations in the use of cesarean delivery for dystocia: Lessons about the source of care. Medical Care, 30, 126135.

[45] Savage, W. and Francome, C. (1993) British caesarean section rates: Have we reached a plateau? British Journal of Obstetrics and Gynaecology, 100, 493-496.

[46] Rock, S.M. (1988) Malpractice premiums and primary cesarean section rates in New York and Illinois. Public Health Reports, 103, 459-463.

[47] Localio, A.R., Lawthers, A.G., Bengston, J.M., Hebert, L.E., Weaver, S.L., Brennan, T.A., et al. (1993) Relationship between malpractice claims and cesarean delivery. Journal of the American Medical Association, 269, 366373.

[48] Griffin, L.P., Heland, K.V., Esser, L. and Jones, S. (1998) Overview of the 1996 professional liability survey. American Congress of Obstetricians and Gynecologists Clinical Review, 3, 1-2, 13-14. 